

\section{Migración y Remesas en Olancho, Honduras $^{1}$}

Manuel Antonio Flores Fonseca²

\section{ANTECEDENTES}

Honduras no ha sido un país muy atractivo para inmigrar, el porcentaje de extranjeros nunca ha superado el $5 \%$ de la población. Sus mayores porcentajes fueron alcanzados en las décadas del veinte, treinta y más modernamente en los años sesenta. En el último censo de población del 2001 no alcanzó ni a uno por ciento. En términos absolutos la franja de extranjeros se ha situado entre veintiocho y cincuenta mil personas en todas las épocas de la historia censal hondureña.

En la emigración, tanto las estimaciones directas como las indirectas muestran que a principios de los años ochenta había en el exterior entre 50,000 a 125,000 hondureños. En el censo de los Estados Unidos de América del año 2000 se empadronaron 217,569 personas de origen hondureño y los estados más atractivos fueron Florida, New York, California, Texas y New Jersey. En la Encuesta de Hogares y de Propósitos Múltiples de Honduras del 2006, se estimó que el total de hogares con emigrantes asciende a 179,051 hogares, los cuales representan aproximadamente el $11.3 \%$ del total nacional, el 53\% se ubican en el área urbana y el 47\% en el área rural. La estructura de la población emigrante tiene un perfil joven comprendida entre 20 y 34 años de edad. Los Estados Unidos es el principal país de atracción para los hondureños, ya que en promedio el 91.4 por ciento de la población total emigrante reside en este país; el 2.2 por ciento en México; el 2.1 por ciento en España y 1.9 por ciento en Centroamérica y el restante diseminados en diferentes países del mundo.

En la migración internacional desde la segunda mitad de la década de los noventa el flujo de emigrantes se ha venido incrementando por las deplorables condiciones económicas del país, con una mayor aceleración después del fenómeno natural que azotó el país en 1998 (Mitch), y no es casualidad que incluso los Estados Unidos de América aprobaran Programas de Protección Temporal (TPS) para frenar la emigración, sin embargo, el mecanismo más usado es la deportación de grandes contingentes de hondureños desde el país del norte y a este se suman los países de la travesía. Sin duda, la emigración hondureña ha alcanzado dimensiones de importancia y si bien ha producido impactos positivos como un gran flujo de remesas (convertida en una de las principales fuentes de divisas del país), ha provocado otros impactos como problemas de desintegración familiar, mutilaciones y muertes en el camino en la búsqueda del sueño americano.

Olancho, el departamento de mayor extensión territorial de Honduras, siempre ha estado inmerso en procesos migratorios a través de su historia, no está de más decir de los flujos que llegaron al departamento procedentes de todo el país, e incluso de El Salvador, en la búsqueda de tierras en la frontera agrícola, a su vez también fue receptor de inmigrantes de Nicaragua en los años ochenta por el conflicto armado en el vecino país. Fue contribuyente de población que buscó empleo en las compañías bananeras en la Costa Norte del País. En los últimos años, tiene un saldo migratorio interno negativo, patrón que es similar a nivel internacional, que ha convertido al departamento con mayores recursos naturales del país en uno de los mayores expulsores de personas al exterior, que aumentó desde el paso del Huracán Mitch y tiene un crecimiento acelerado en los últimos años. 
Los nacidos en Olancho tienen características particulares, una imagen sólida de machismo, lazos familiares muy extensos, identificación fuerte con su terruño de nacimiento, costumbres, cultura gastronómica especial, patrones y costumbres culturales arraigadas y utilización de términos particulares en su lenguaje. Todos estos elementos de arraigo se incluyen en los procesos migratorios desde el punto de vista cultural que hacen de la emigración olanchana un flujo especial. Esto llevó a una organización no gubernamental ${ }^{3}$ con experiencia en temas del desarrollo a estudiar detenidamente el fenómeno en esa zona para desarrollar políticas y estrategias de apoyo a las comunidades.

\section{PLANTEAMIENTO DEL PROBLEMA}

El acto de migrar es parte de una estrategia de vida que a través del traslado a un lugar lejano, se buscan más oportunidades de empleo donde los salarios percibidos son mayores que los que se obtienen en el lugar de salida. Al tomar la decisión de migrar se buscan los medios para llevarla a cabo y los canales o redes que se utilizarán para ello. Si bien es cierto, que llevar a cabo el traslado con éxito puede significar el poder mejorar las condiciones de vida del emigrante y sus familiares en el país de origen, también puede significar desmejorar las condiciones de vida, cuando los lazos afectivos con la familia en el país de origen se pierden o cuando las oportunidades laborales disminuyen y se encarece el nivel de vida en el lugar de emigración.

El emigrante ya insertado en el mercado laboral del país de acogida envía una parte de su salario a través de la remesa, misma que no solamente es el medio de ayuda económica a los suyos, sino una manera de expresar sus sentimientos de nostalgia a los receptores. Estas remesas no solamente tienen un impacto positivo a nivel micro en los hogares receptores al mejorar las condiciones de vivienda, el acceso a alimentos, educación, salud y otras necesidades, sino también a nivel local (comunitario) porque ensanchan la economía local al agrandar y mover la masa monetaria en la comunidad por la compra venta de productos y servicios locales. A su vez el mayor beneficio se obtiene en la economía regional que provee los productos y servicios que no puede cubrir la comunidad y que son buscados en las ciudades de la región, que a su vez son suplidas por los grandes centros de producción nacional e internacional.

La emigración también produce impactos negativos a nivel de los hogares al romper las estructuras de los hogares y producir desintegración familiar y hacer que la crianza de los hijos recaiga en los familiares en el país de origen. Otro aspecto negativo de la emigración cuando se envían remesas es la dependencia económica de esta que incluso afecta para que los receptores busquen trabajo o generen emprendimientos. A nivel comunitario los hogares que tienen emigrantes y reciben remesas son percibidos por los que no tienen emigrantes y no reciben remesas, como grupos privilegiados que tienen mejores condiciones de vida y que no se involucran tanto en las actividades productivas y comunitarias.

La emigración en Olancho como fenómeno social ha tenido impactos positivos y negativos en la región, en el ámbito local y a nivel del hogar. Este trabajo es una aproximación a encontrar evidencias de algunos impactos que producen la emigración y las remesas en las poblaciones en el lugar de origen.

\section{FUENTES DE INFORMACIÓN}

La fuente principal de información para este trabajo es una Encuesta de Hogares de Migración y Remesas en Olancho, diseñada con el objetivo de caracterizar demográficamente y socioeconómicamente a la población, las características de las viviendas, la población con experiencia migratoria, el perfil de los emigrantes, las remesas y sus usos e impactos en los hogares y sus comunidades. Otras fuentes de información utilizadas fueron de carácter cualitativo que significaron la utilización de técnicas participativas para un mayor involucramiento de todos los actores involucrados con el fenómeno en la región. 


\section{METODOLOGÍA.}

La investigación sobre migración y remesas en Olancho se enmarca en una metodología de investigación no tradicional, ya que por un lado se utilizaron elementos de la investigación participativa, donde la población estudiada se involucró en el proceso a través de la organización comunitaria y de familiares de remesantes, lo mismo que se utilizaron investigadores locales que participaron activamente en la investigación. Por otro lado, fueron tan altas las expectativas de la investigación que los involucrados han utilizado elementos de la investigación acción, con la organización de acciones de desarrollo, entre ellas la creación de una cooperativa de ahorro y crédito con los familiares de remesantes y a su vez llevó al diseño y ejecución de un proyecto de desarrollo económico local en la cual participan todos los actores involucrados.

La amplia gama de fuentes de recolección de fuentes cuantitativas y cualitativas llevó a poner en práctica muchas técnicas de investigación y para la cual cada una de ellas desarrolla una metodología de aproximación a los sujetos de investigación.

En el caso de la Encuesta de Hogares de Migración y Remesas, que es la fuente principal de datos de este trabajo, se seleccionó una muestra de 1,099 hogares en los cuatro municipios con mayores flujos migratorios del departamento, (Juticalpa, Catacamas, Santa María del Real y San Francisco de Becerra). Estos cuatro municipios tienen una población aproximada de 232,057 habitantes que representan el $49.3 \%$ de la población total y $45.7 \%$ de la extensión territorial del departamento. El muestreo fue polietápico. Aunque la encuesta es una fuente de carácter cuantitativo construyó un marco muestral generado de mapeos municipales, que con la utilización de técnicas participativas concientizó a los actores de las comunidades para formar grupos de apoyo a los investigadores locales, para después elegir las comunidades de estudio a profundidad, esta es la primera etapa (selección de información de todas las comunidades para selección de 16 unidades primarias de muestreo). En una segunda etapa, con los grupos de apoyo se recolectó información general de los hogares de todas las comunidades de la región, se aplicaron formularios de carácter estadístico a nivel comunitario para identificar hogares que podrían ser seleccionados en la muestra (selección de información de todos los hogares de las 16 unidades primarias de muestreo seleccionadas, para conformar las unidades primarias de selección).

La encuesta recolectó información en varios capítulos, el primero de identificación geográfica y muestral, el segundo sobre las características de las viviendas, el tercer capítulo sobre las características de las personas donde se rescató información demográfica, el cuarto sobre las características educativas de la población, el quinto sobre las características económicas de la población, el sexto recogió información sobre la experiencia migratoria de las poblaciones, el séptimo sobre las características de los emigrantes internacionales, el octavo sobre las remesas, el noveno sobre el costo y gestión de la remesa y el último sobre uso, ahorro e inversión de la remesa.

\section{RESULTADOS}

\subsection{Perfil del Emigrante Olanchano.}

En el 28\% de los hogares de la región de estudio salió alguna persona que vive actualmente en otro país. El número de emigrantes es 22,824 personas, casi un décimo de la población actual. La mayoría son hijos o hijas del jefe actual del hogar, en menor medida son cónyuges y hermanos, existiendo mayor predisposición en cónyuges cuando son hombres, e hijas cuando son mujeres.

Han salido del país desde edades de la infancia hasta las edades adultas maduras. En general, migran más hombres que mujeres, e incluso sus edades abarcan más años que en las mujeres. Cuando emigraron en su mayoría tenían entre 18 a 30 años de edad, lo que indica que son jóvenes y en edades productivas. Cuando salieron del país eran cinco años más jóvenes en promedio. La edad promedio del emigrante cuando se fue era de 25.4 años, la actual es 30.8 años.

Más de la mitad de los emigrantes tenía o había tenido alguna relación de convivencia con una pareja, los informantes 
dicen que el 46\% era casado o unido. Un 47\% era soltero y el resto tenía otra relación de convivencia o era menor de edad. En las mujeres se encontraron mayores casos de separación, divorcio y viudez que sin duda pudieron ser unas de las mayores causales de la emigración.

El nivel educativo del emigrante no puede ser considerado tan bajo en la región, aunque dos tercios de ellos sólo han cursado algún grado de la educación primaria, lo cierto que de ellos casi la misma relación ha cursado el nivel completo, o sea al menos seis años de educación. Un 27.6\% de los emigrantes cursó un nivel de educación mayor a la primaria, como ser educación media o superior, e incluso los que han cursado esos niveles más de dos tercios de ellos han terminado el nivel medio y un tercio de terminaron el nivel superior. Las mujeres que emigraron tienen un nivel de educación mayor que los hombres. El promedio de años de estudio de los emigrantes era de 5.4 años de estudio, que aunque indica un promedio bajo de estudios, es superior al de la población de la región, cuyo promedio es de 3.6 años.

La emigración de estos municipios de Olancho se remonta desde inicios de los años ochenta, sin embargo, a partir de los noventa es que continuó, en los años 1998 y 1999 es cuando se dispara el flujo de emigrantes, un hecho significativo de estos años fue el paso del Huracán Mitch, que además de provocar la muerte de muchas personas y destrucción de viviendas, caminos y cultivos, produjo un sentimiento de desesperanza que llevó a las personas a buscar nuevos horizontes en el exterior, que se vieron favorecidos cuando algunos de ellos tenían familiares en el exterior. La mayor corriente de emigrantes olanchanos es a partir del año 2000 y es creciente cada año, más de la mitad de los emigrantes de la zona han salido recientemente del país. El flujo emigratorio básicamente se produce en los primeros meses del año en mayor medida, principalmente en el verano, siendo los meses de marzo, abril y mayo los de mayores salidas. Una excepción fue octubre de 1998 cuando ocurrió el Mitch.

Más de un tercio de los emigrantes dejó cónyuge cuando salió del país. El porcentaje de emigrantes hombres que dejaron cónyuge es más del doble que las mujeres. Más de la mitad de los emigrantes dejaron hijos en el país cuando salieron, los hombres dejaron más hijos, 2.4 veces más hijos que las mujeres. El número total de hijos dejados en el país supera el número de emigrantes lo que indica el alto grado de desintegración familiar producto de la emigración. Los hijos de emigrantes prefirieron dejarlos a cargo de su madre, esposa o de su abuela, esto porque en su mayoría son hombres y prefieren dejar a sus hijos con mujeres, incluso cuando las que emigran son mujeres no dejan a cargo a sus hijos a hombres. Un porcentaje no despreciable declara que los emigrantes dejaron solos a sus hijos.

Los emigrantes en su mayoría trabajaban al momento de irse del hogar, prueba de esto es cuatro de cada cinco de ellos trabajaba o estudiaba y trabajaba, o tenían un negocio, lo que indica que eran altamente productivos. En el caso de las mujeres, es lógico que deban tener un menor valor de actividad económica, sin embargo, los porcentajes indican que era superior a las mujeres que no migraron. Esto resultados pueden indicar que no es la falta de trabajo una de las causas de emigración, más cerca puede ser la calidad del trabajo que realizaban. Los emigrantes trabajaban al momento de irse del país en las ocupaciones relacionadas con la agricultura y en menor medida en los servicios y comercio.

Las principales causas para emigrar son superar la pobreza, buscar nuevos horizontes que está ligado a la situación de pobreza y poder comprar su casa. En realidad, casi todas las causas están relacionadas, sin embargo, la poca generación de ingresos, mala calidad de empleo o fuentes de trabajo y la pérdida de las expectativas de mejoramiento son causas que están incidiendo a la salida de personas al extranjero.

La mayoría de los emigrantes salió del país utilizando como forma de viajar tomando los servicios de un guía o coyote y en menor medida dijeron que viajaron por su cuenta. Muy pocos utilizaron una visa de entrada a otro país como forma de llegar al destino final. También se observa que nueve de cada diez personas que salieron del país de la zona utilizaron formas no seguras para migrar al exterior. 
Como destino final los Estados Unidos de América tenían los emigrantes y casi la totalidad pudo conseguir llegar a su destino, muy pocos casos de las personas que salieron de la región no culminaron con éxito el país de destino final, y se quedaron en México o no saben el país donde residen ellos actualmente, otro número menor tenía como destino México pero vive en los Estados Unidos, lo que muestra que el destino final era en realidad el gran país del norte. Los estados donde viven los emigrantes de la región son Florida, Nueva York, Massachusetts y Missouri. Las ciudades donde residen en su mayoría los emigrantes olanchanos son Miami, Nueva York, Boston, San Luís.

Más de la mitad de los emigrantes de la región no tienen papeles que acredite que viven legalmente en el país de destino, incluso un $8 \%$ de ellos los informantes no saben con certeza cual es la situación migratoria en el exterior. Actualmente los emigrantes están participando en la actividad económica, prueba de ello es que el $94 \%$ de ellos trabaja en el país de residencia. En las mujeres también hay un nivel alto de participación económica. Las ocupaciones del emigrante en el país de destino son generalmente como obreros, como operarios, oficios, servicios y vendedores. Claramente se muestra que en el lugar de origen las personas se dedicaban a la agricultura en cambio en el país de destino generalmente son obreros que se dedican a los servicios.

Ocho de cada diez emigrantes piensa volver al país y las principales razones cuando piensa volver es cuando tenga papeles en el país de destino y cuando tenga los medios, cuando construya su casa. Un porcentaje muy reducido ha afirmado que no piensa volver al país.

Los canales de comunicación entre los emigrantes y sus familiares son muy fluidos, un $93 \%$ se comunica con sus hogares, la frecuencia de comunicación más alta es aquella que se hace semanalmente lo que indica que los lazos de comunicación entre los emigrantes y sus familias son muy fuertes. Muy pocos emigrantes han perdido comunicación con sus familiares. La inmensa mayoría utiliza el teléfono como medio de comunicación.

\subsection{Experiencia Migratoria de la Población.}

En más de un décimo de los hogares (11.4\%) de la región viven personas que han realizado un viaje fuera de Honduras. Hay un total de 6,306 personas que tienen experiencia migratoria en la región. La mayoría tuvieron en su última experiencia como destino los Estados Unidos de América. De los que iban a EUA 1,004 llegaron hasta México, representan un 17\% de los que iban en deseo de cumplir el sueño americano y no lo cumplieron.

La mayoría (73\%) de las personas realizaron la última experiencia migratoria después del año 2000, donde el flujo de personas emigrantes se acrecentó. El medio de transporte que se utilizó en mayor medida fue la vía terrestre, lo que indica que muchas de las experiencias no fueron de carácter seguro. Los motivos que tuvieron los que experimentaron la migración para regresar al país en casi dos tercios de ellos admiten fue por su propia voluntad o fue planificado. Un 30\% admite contundentemente que fue deportado por las autoridades de otro país.

\subsection{Las Remesas en Olancho.}

Más de un tercio de los hogares de la región reciben remesas, que incluso supera el porcentaje de hogares en cuya condición migratoria aduce tener emigrantes en el exterior. Un total de 81,201 personas viven en hogares que reciben remesas (tengan o no emigrantes en el hogar), es decir están directamente beneficiados de las remesas.

El parentesco del principal receptor de la remesa con el emigrante en mayor medida está relacionado con el sexo femenino, dos tercios de los que reciben la remesa son la madre, esposa, hermana, hija y abuela, aunque es de esperarse porque los emigrantes en su mayoría son hombres.

En el monto de la remesa los mayores porcentajes se ubican en menores de mil lempiras, ${ }^{4}$ el segundo lugar entre tres y cinco mil lempiras. El monto promedio mensual de la remesa asciende a 3,470 lempiras. 
Gráfico No. 1. Olancho: Monto mensual de las remesas

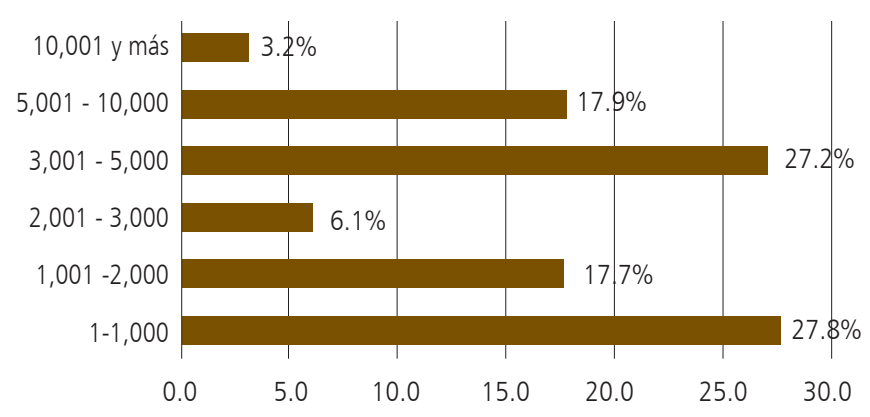

La frecuencia de envío de la remesa es mayoritariamente cada mes o cada quince días, lo que indica la importancia de ese flujo de dinero en las familias. Las compañías remesadoras Western Unión y Money Gram son los principales canales de envío de las remesas en la región. Más del noventa porciento de los receptores de remesa solo hace un intento para cobrar la remesa. Las dos principales ciudades de la zona (Catacamas y Juticalpa) son los lugares donde en mayor medida se cobra la remesa.

La seguridad alimentaría, la educación y la salud son los principales usos que hacen los hogares que reciben remesas, en el 91\% de los hogares se afirma utilizar la remesa para alimentarse (nueve de cada diez receptores, mientras que sólo uno no la utiliza para esto), un 86\% la utiliza también para sufragar gastos relacionados a la educación de los hijos y un $83 \%$ para cubrir costos de salud. De los hogares receptores, el 40\% utiliza la remesa para transporte, este dato se encuentra asociado al traslado diario que los jóvenes estudiantes de ambos sexos realizan para asistir a clases desde sus comunidades rurales hasta las ciudades principales, que es donde se encuentran los centros educativos de educación media y universitaria en la región. Es claro que los montos y porcentajes destinados para la educación y la salud ocupan los primeros lugares en la mayoría de las familias receptoras de remesas, lo que se encuentra directamente asociado a la ausencia de educación pública de calidad y de los servicios estatales de salud, razón por la que las familias envían a sus hijos e hijas a escuelas privadas ubicadas en las ciudades de mayor concentración poblacional y desarrollo relativo, como son Juticalpa y Catacamas, lo que encarece los costos de dichos servicios, recayendo en los esfuerzos de los familiares emigrantes. De ahí que desde un punto de vista estratégico y de tiempo, ambas constituyen inversiones sociales de largo plazo.

Después de los usos familiares, los hogares están utilizando poco la remesa para la inversión. Sólo un 1\% ha invertido en otros activos fijos como terrenos, compra de ganado, fincas, vehículos, etc. Además, se evidencia que la gran mayoría de los receptores no son en realidad personas con capacidad para invertir o ahorrar en grandes cantidades. Con lo que se intuye que la remesa está sirviendo para sustento familiar (consumo), principalmente. Sólo un $15 \%$ de las familias receptoras está ahorrando dinero de la remesa. Otro aspecto en los hogares receptores, es que además de cubrir sus necesidades básicas, logran adquirir algunos bienes como, electrodomésticos, teléfonos, artículos para el hogar, ropa, etc., y esta capacidad de consumo refleja en otras familias no receptoras la idea de que la única forma de superar la pobreza es a través de la emigración.

Del total de hogares receptores de remesa, sólo un $5 \%$ ha utilizado la remesa en vivienda y, de este porcentaje, el principal uso de la remesa son las mejoras, evidencia que pudo constatarse en las características de vivienda de la encuesta de hogares, donde predominan las paredes de concreto, el piso de cemento y el servicio sanitario conectado a pozo o red de alcantarillado.

La percepción de los pobladores de las comunidades indica que la ganadería es uno de los rubros favoritos de los emigrantes. Un 29\% del total invertido está en la compra de ganado, al que debe sumársele el 15.2\% utilizado en compra de potreros, así que este rubro está teniendo la mayor inversión de la remesa en la zona (un $44.6 \%$ del total de la remesa destinada a otros activos fijos), mientras que las fincas sumadas a los terrenos agrícolas sólo alcanzan un $28 \%$ del total.

En cuanto a los negocios realizados con inversión parcial de las remesas, los datos de la encuesta señalan que un 52.3\% de éstos son pulperías; un 15.7\% lo destinó a la compra de bueyes para el acarreo de materiales y un 
$11.8 \%$ para instalar cafeterías, como se observa la mayor inversión se encuentra en las pulperías que comercializan productos de consumo básico y no requieren de montos elevados para operar. En orden descendente aparece la venta de ropa, calzado, perfumes y cosméticos con un 5.0\%. Resulta interesante observar que sólo un 1.9\% ha invertido parcialmente en agricultura para el cultivo del maíz.

Con relación a si han logrado hacer algún tipo de negocio o emprendimiento familiar, apenas un 1.5\% respondió tener un negocio con fondos totales provenientes de remesas, y un $2.0 \%$ respondió que ha financiado parcialmente su negocio con dinero de las remesas.

\subsection{Migración y Remesas}

En la relación entre la migración y las remesas, se verificó el número de hogares donde han salido emigrantes al exterior y también el número de hogares que reciben remesas. Al cruzar estas dos variables encontramos que la mayoría de los hogares en Olancho no tienen emigrantes ni reciben remesas (62\%), en segundo lugar se encuentran los hogares que tienen emigrantes en el exterior y que reciben remesas $(24.8 \%)$, en tercer lugar se encuentran los hogares que no tienen emigrantes pero que reciben remesas $(10.2 \%)$ y en último lugar están los hogares que tienen emigrantes pero que no reciben remesas (2.8\%). De ellos sorprende el porcentaje de hogares sin emigrantes y que recibe remesas cuyo origen puede estar en la fuerte solidaridad que existe entre la población de la región y en los lazos familiares extensos que rebasan la condición residencial del hogar, pero que está ligado a la familia en la mayoría de los casos.

En el caso del número de habitantes que vive en estos hogares, los que reciben remesas y tienen emigrantes suman 59,477 personas y los que reciben remesas y no tienen emigrantes suman las 21,725 personas (gráfico No. 2).

\subsection{Impactos de la Migración y Remesas en Olan- cho}

Con los resultados de la Encuesta de Hogares en Olancho se construyeron algunas tabulaciones que permitieran aproximaciones a algunos impactos de la

\section{Gráfico No. 2. Olancho: hogares por condición migratoria según recibo de remesas}

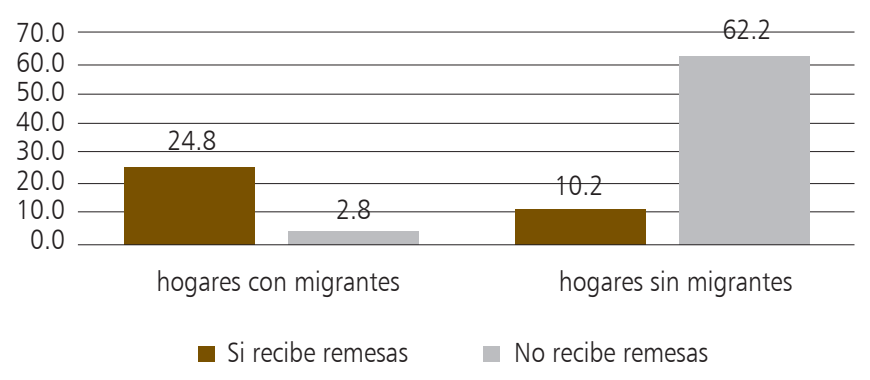

migración y las remesas en los hogares de la región. Se formaron grupos de poblaciones que viven en hogares con emigrantes y sin emigrantes y poblaciones que viven en hogares con remesas y sin remesas. Las áreas que se estudiaron son: las condiciones de las viviendas, las características demográficas, educativas, fuerza de trabajo y estructuras familiares.

\subsubsection{Diferencias en las Condiciones de las Vivien- das entre Hogares Receptores y No Receptores de Remesas.}

Se construyó una caracterización de las condiciones de las viviendas de los hogares que reciben remesas y los que no reciben. En el tipo de vivienda existe una mayor predisposición a vivir en vivienda independiente cuando se reciben remesas en el hogar. En los materiales predominantemente usados en las paredes y pisos de las viviendas se observa más predisposición a usar materiales durables cuando se reciben remesas.

En el acceso a agua potable, hay mayor predisposición a tener tubería de agua, conexión de tubería a red de servicio privado y tenerla dentro de la vivienda cuando se reciben remesas que cuando no se reciben. Hay mayor acceso y exclusividad a sistemas de eliminación de excretas en las viviendas, cuando se reciben remesas. Lo mismo pasa, en el acceso a electricidad en las viviendas y acceso a energía para cocinar, cuando se reciben remesas.

El número de piezas en las viviendas es mayor, la tenencia de vivienda es propia y tenencia de vehículos en el hogar es superior cuando se reciben remesas. En general, puede afirmarse que los hogares que reciben remesas tienen mejores 
condiciones de vivienda que aquellos que no reciben, aunque esta mejora no es espectacular, sí permite una ventaja y es un aliciente de la emigración al exterior (gráfico No. 3).

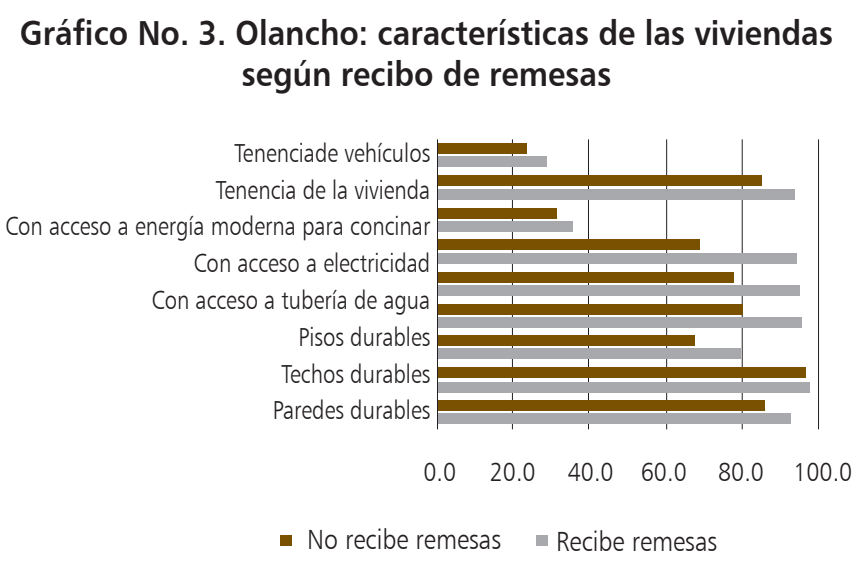

\subsubsection{Diferencias Demográficas en Poblaciones Con} Migrantes y Sin Migrantes.

La población total de los cuatro municipios estudiados según nuestra estimación asciende a 232,057 que representa el 49.3\% de la población del departamento. La estructura por edad es joven, con una pirámide de carácter expansivo con una base ancha que va disminuyendo hasta tener una cúspide estrecha, en ella en el caso de la población masculina y en las edades jóvenes se observan reducciones producto de la emigración. En la población de los hogares donde hay emigrantes hay grandes reducciones en las edades jóvenes y adultos jóvenes.

El índice de masculini$\operatorname{dad}^{5}$ para la población total es de 94.1 que muestra que es menor el número de hombres con respecto a las mujeres. En los hogares con migrantes el indice de masculinidad asciende a $89.4 \mathrm{y}$ los hogares sin migrantes es de 95.9, lo que indica que los primeros tienen menos hombres.
El promedio de edad en la región es de 23.8 años, es mayor casi dos años en las poblaciones de hogares con migrantes que en hogares sin migrantes. Esta estructura demográfica hace que en la región, la relación de dependencia sea de 87.3. En los hogares con migrantes la relación de dependencia ${ }^{6}$ de la población asciende a 88.2 y los hogares sin migrantes a 87.0, lo cual muestra leves diferencias entre ambas (gráfico No. 4).

Existe una mayor diversificación en las relaciones de parentesco cuando hay emigrantes en el hogar. Un tercio de la población de la zona declara estar en unión conyugal, ya sea como casado o unión libre. Un diez por ciento de la población femenina tiene un estado civil en ruptura, ya sea separada, divorciada o viuda. Más de un sesenta por ciento declara ser soltero o menor de doce años.

\subsubsection{Diferencias Educativas de las Poblaciones Con Migrantes y Sin Migrantes.}

La condición de alfabetismo en la zona de estudio es relativamente baja (75.6\%) y en los hogares donde hay emigrantes es más alta en un $8 \%$, que donde no hay emigrantes, lo que indica que hay mejores niveles de alfabetismo en hogares donde hay emigrantes.

La asistencia escolar de la población gira alrededor de $35 \%$ y es más alta entre las edades de cinco a veinticuatro
Gráfico No. 4. Población por edad y condición migratoria del hogar

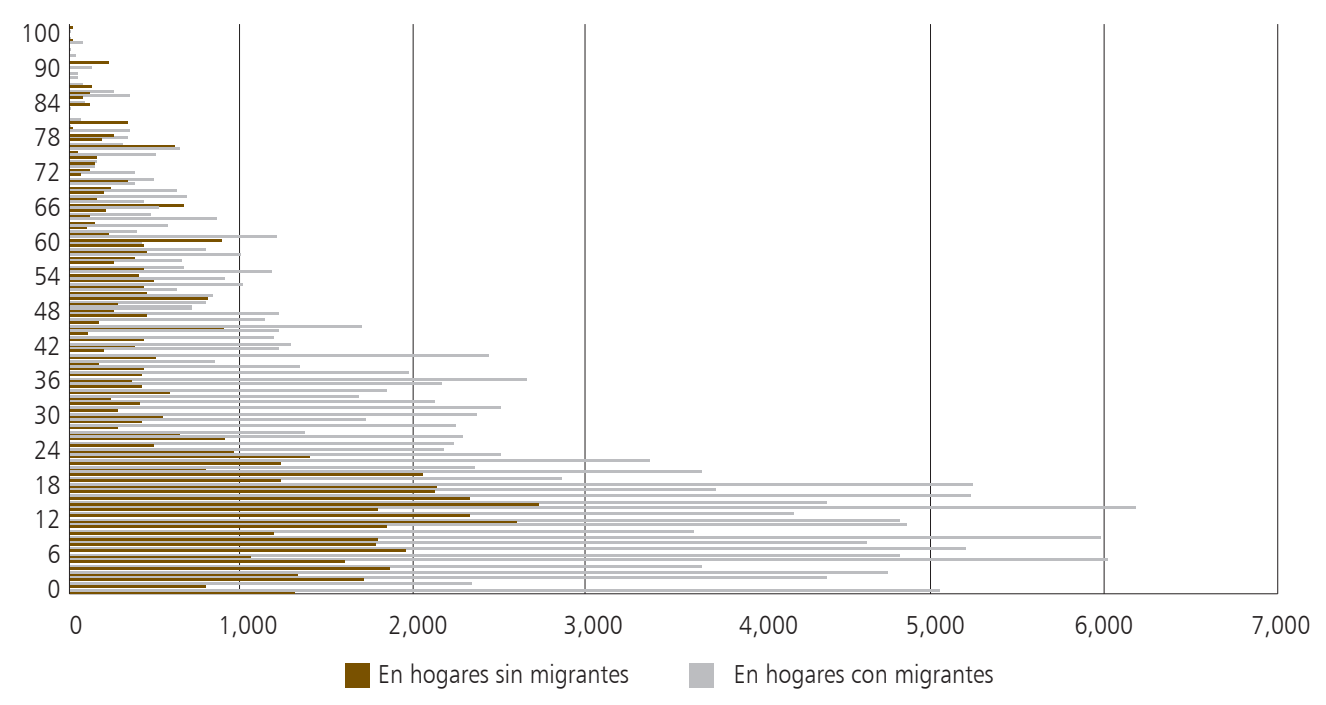


años. Cuando hay emigrantes en el hogar la asistencia es mayor en casi ocho por ciento que la de la población que vive en hogares sin emigrantes.

Los niveles educativos de la población son bajos, sólo el 57\% del total de la población ha alcanzado algún grado de la educación primaria. Apenas un 9\% ha cursado el ciclo común, sólo un 7.6\% han logrado alcanzar el nivel secundario y un $1.4 \%$ ha cursado algún año de educación superior. Los niveles educativos de la población de hogares con emigrantes son mayores que en aquellos hogares donde no hay emigrantes.

\subsubsection{Diferencias Económicas de las Poblaciones entre Poblaciones Con Migrantes y Sin Migrantes.}

La población en edad de trabajar (PET) dentro de la región de estudio representa el 82\% de la población total. Sólo el 38\% de la PET conforma la Población Económicamente Activa (PEA) y por sexo las diferencias son abismales a favor de los hombres, los niveles de ocupación formal por parte de mujeres son bajísimos. Las tasas brutas de participación económica (TBP) son bajas, ya que existen sólo 31 personas económicamente activas por cada cien habitantes. Las diferencias por sexo, muestran que los hombres tienen un indicador tres veces superior al de las mujeres en la participación de actividades productivas. Las tasas netas de participación económica (TNP) muestran a nivel total un valor de 38\%, los hombres alcanzan 60\%, mientras las mujeres sólo el 18\% (gráfico No.5).

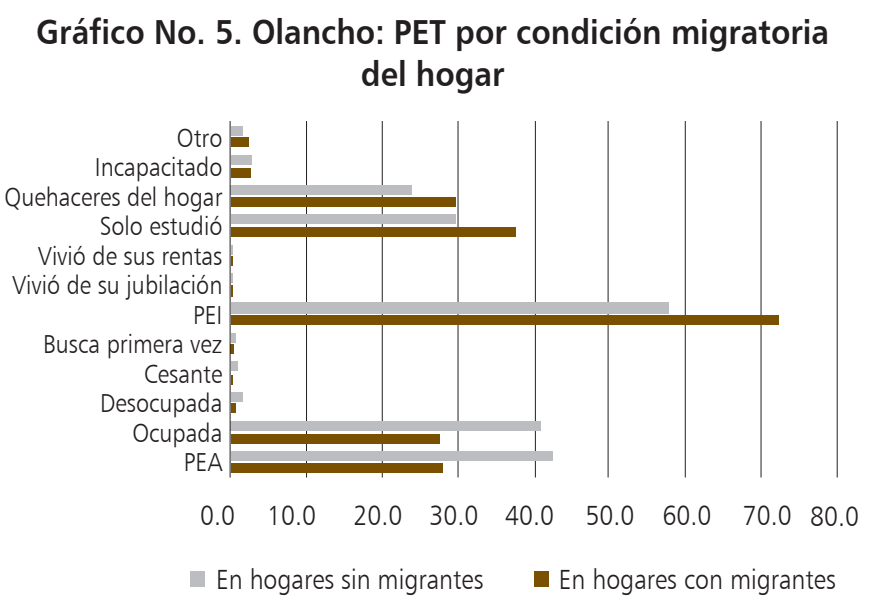

El hallazgo más relevante es la PEA y la PEA ocupada es menor cuando hay emigrantes en el hogar y es mayor la Población Económicamente Inactiva (PEI) cuando hay emigrantes en el hogar. En esta relación hay varios factores entre ellos se puede mencionar que en los hogares con emigrantes un destino de las remesas se dedica a lograr que los niños estudien y por otro lado la seguridad de acceder a un flujo de dinero constante mella en el interés por trabajar.

En los ingresos mensuales menores de dos mil lempiras la población de hogares sin migrantes son mayores que los con migrantes, pero a partir de ingresos mayores de dos mil hasta veinte mil lempiras la población de los hogares con migrantes son mayores, en los ingresos superiores de veinte mil lempiras se encuentran en las poblaciones de hogares sin migrantes. El promedio de ingresos de la población total asciende a 5,162.19 lempiras, en la población de hogares con migrantes a 3,694.29 lempiras y en la población de hogares sin migrantes a 5,493.45 lempiras. Estos resultados revelan una franja de ingresos medios en los hogares con migrantes con respecto a los que no tienen migrantes que están en los estratos bajos y altos (gráfico No. 6).

\section{Gráfico No. 6. Ingreso mensual de la población por condición migratoria del hogar}

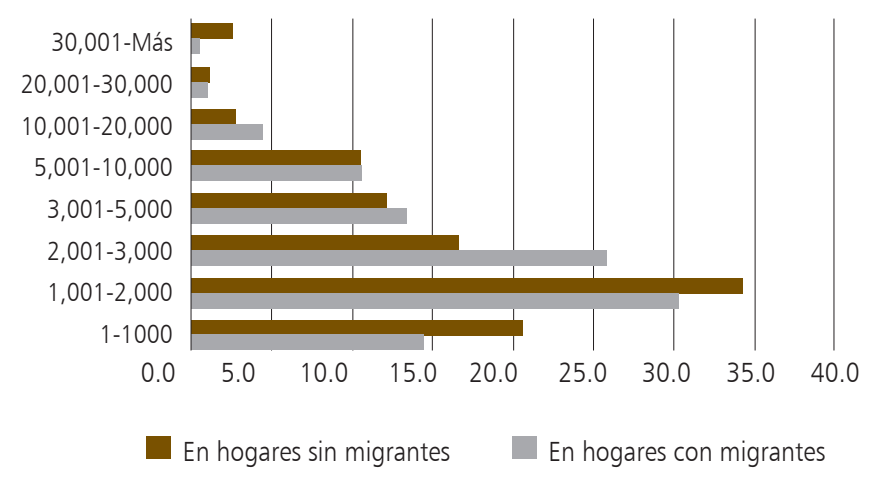




\subsubsection{Diferencias entre Estructuras de los Hogares} Con Migrantes y Sin Migrantes.

Los hogares familiares que tienen migrantes son generalmente extendidos, en cambio los hogares sin migrantes son nucleares. Este hallazgo es efecto de la emigración.

Los hogares familiares con migrantes giran en torno a arreglos familiares conformados por pareja e hijos y jefe solo e hijos, casi en igual proporción, con los agregados familiares en el caso de los extendidos y los agregados familiares y no familiares que son los compuestos. Hay un menor porcentaje de hogares no familiares unipersonales con migrantes.

En cambio los hogares sin migrantes se estructuran generalmente como hogares conformados por pareja e hijos, con los agregados familiares y no familiares. Los hogares unipersonales sin migrantes son levemente mayores que los hogares con migrantes.

Mientras en los hogares con migrantes las diferencias entre biparentales y monoparentales son minúsculas, en los hogares sin migrantes los biparentales son mayoría. Esto indica que los hogares con migrantes han sufrido grandes cambios estructurales porque uno de los miembros de la pareja no esta en el hogar.

\section{Gráfico No. 7. Tipos de hogar por condición migratoria}

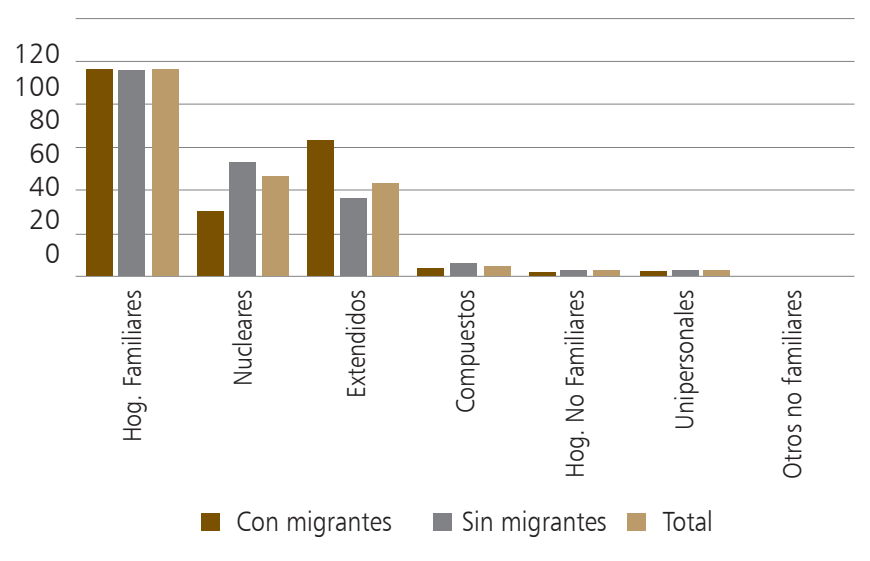

Existe en la región de estudio un porcentaje alto de jefaturas femeninas a nivel general, que es agravado cuando en los hogares hay emigrantes en el exterior y casi existe la misma proporción entre jefas con respecto a los jefes. En las tasas de jefatura según la condición migratoria y sexo del jefe se observa como las mujeres asumen las jefaturas de los hogares en las edades de emigración, desde 20 a 40 años principalmente. 


\section{Cuadro No. 1. Olancho: Estructura de los Hogares por Tenencia de Migrantes}

\begin{tabular}{|c|c|c|c|}
\hline Tipos de Hogares & Con migrantes & Sin migrantes & Total \\
\hline Hogares Familiares & 97,6 & 96,5 & 96,8 \\
\hline Nucleares & 30,4 & 53,6 & 47,2 \\
\hline Jefe Conyuge e hijos & 14,6 & 45,2 & 36,7 \\
\hline Jefe solo e hijos & 15,7 & 7,9 & 10,0 \\
\hline Jefe, Conyuge e hijos y empleada & 0,2 & 0,3 & 0,3 \\
\hline Jefe e hijos y empleada & 0,0 & 0,2 & 0,1 \\
\hline Extendidos & 63,7 & 36,9 & 44,2 \\
\hline Jefe, conyuge, otro pariente & 11,0 & 3,9 & 5,9 \\
\hline Jefe, conyuge e hijos, otro pariente & 20,9 & 18,5 & 19,1 \\
\hline Jefe solo e hijos, otro pariente & 22,6 & 9,6 & 13,2 \\
\hline Jefe solo, otro pariente & 8,7 & 4,7 & 5,8 \\
\hline Jefe, conyuge, hijos, otro pariente, doméstico & 0,5 & 0,2 & 0,3 \\
\hline Compuestos & 3,6 & 6,1 & 5,4 \\
\hline Jefe, conyuge, otro no pariente & 0,0 & 1,2 & 0,9 \\
\hline Jefe, conyuge, hijos, otro pariente, otro no pariente & 2,1 & 3,4 & 3,1 \\
\hline Jefe, conyuge, otro pariente, otro no pariente & 0,0 & 0,1 & 0,1 \\
\hline Jefe, conyuge, hijos, otro pariente, otro no pariente, doméstico & 0,2 & 0 & 0,1 \\
\hline Jefe solo, otro pariente, otro no pariente & 0,3 & 0,2 & 0,3 \\
\hline Jefe solo, otro no pariente, doméstica & 0,0 & 0,1 & 0,1 \\
\hline Jefe, conyuge, otro pariente, otro no pariente, doméstico & 0,1 & 0,0 & 0,0 \\
\hline Jefe, conyuge, hijos, otro no pariente & 0,0 & 0,1 & 0,1 \\
\hline Jefe solo, hijos, otro pariente, otro no pariente & 0,8 & 0,9 & 0,9 \\
\hline Hogares No Familiares & 2,4 & 3,5 & 3,2 \\
\hline Unipersonales & 2,4 & 3,1 & 2,9 \\
\hline Unipersonales y empleada & 0 & 0,1 & 0,1 \\
\hline Otros no familiares & 0,0 & 0,0 & 0,0 \\
\hline Jefe y otro no familiar & 0 & 0,3 & 0,2 \\
\hline Total & 100 & 100 & 100 \\
\hline
\end{tabular}

Fuente: Encuesta de Hogares de Migración y Remesas, RDS. 
CITAS

1. Trabajo presentado en el III Congreso de la Asociación Latinoamericana de Población, realizado en Córdoba, Argentina, del 24 al 26 de septiembre de 2008.

2. Profesor del Instituto de Investigaciones Económicas y Sociales de la Universidad Nacional Autónoma de Honduras. Investigador Asociado de la Red de Desarrollo Sostenible de Honduras, Email: maflofo@yahoo.com; www.poblacion.rds.hn .

3. La Red de Desarrollo Sostenible de Honduras (RDS-H) desarrolló la investigación acción "Impacto de la Migración y Remesas en la Economía Local de Olancho" con el patrocinio del Centro Internacional de Investigación para el Desarrollo (CIID) de Canadá. El autor participó como asesor temático en demografía y en el diseño de la investigación, de donde se deprende este trabajo.

4. Lempira, héroe indígena nacional que en su honor se designa la moneda nacional de la República de Honduras, al cambio de 18.90 por dólar al momento de la investigación.

5. Índice de Masculinidad: Es la relación de varones a mujeres en una población dada, que de ordinario se expresa como el número de varones por cada cien mujeres. En la región hay 102 varones por cada 100 mujeres.

6. Relación de dependencia: Relación entre las personas en edades dependientes (menores de 15 y mayores de 64 años) y las personas en edades económicamente productivas (15 a 64 años). En la región hay 104 personas en edad dependiente por cada cien personas en edades productivas.

\section{BIBLIOGRAFÍA}

RDS-HN. Base de datos Encuesta de Hogares Migración y Remesas en Olancho, Tegucigalpa, RDS-HN, 2007.

Flores Fonseca, Manuel. Informe de Vivienda, Encuesta de Hogares Migración y Remesas en Olancho, Tegucigalpa, RDS-HN, 2007.

Flores Fonseca, Manuel. Informe Características Socio-demográficas, Encuesta de Hogares Migración y Remesas en Olancho, Tegucigalpa, RDS-HN, 2007.

Flores Fonseca, Manuel. Informe Características Educativas de la Población, Encuesta de Hogares Migración y Remesas en Olancho, Tegucigalpa, RDS-HN, 2007.

Flores Fonseca, Manuel. Informe Características Económicas de la Población, Encuesta de Hogares Migración y Remesas en Olancho, Tegucigalpa, RDS-HN, 2007.

Flores Fonseca, Manuel. Informe Estructuras Familiares, Encuesta de Hogares Migración y Remesas en Olancho, Tegucigalpa, RDS-HN, 2007.

Flores Fonseca, Manuel. Informe Experiencia Migratoria, Encuesta de Hogares Migración y Remesas en Olancho, Tegucigalpa, RDS-HN, 2007.

Flores Fonseca, Manuel. Informe Características Socio-demográficas de los Emigrantes, Encuesta de Hogares Migración y Remesas en Olancho, Tegucigalpa, RDS-HN, 2007. 